\title{
Epidemiology of pneumothorax in England
}

\author{
Dheeraj Gupta, Anna Hansell, Tom Nichols, Trinh Duong, Jon G Ayres, David Strachan
}

Heartlands Research Institute, Birmingham Heartlands Hospital, Birmingham B9 5SS, UK

D Gupta

J G Ayres

Department of Public Health Sciences, St George's Hospital Medical School, London SW17 0QT, UK A Hansell

T Nichols

T Duong

D Strachan

Correspondence to: Professor J G Ayres email:

ayresi@heartsol.wmids.nhs.uk

Received 5 January 2000 Returned to authors 20 March 2000

Revised version received

3 April 2000

Accepted for publication

18 April 2000

\begin{abstract}
Background-Little is known of the epidemiology of pneumothorax. Routinely available data on pneumothorax in England are described.

Methods-Patients consulting in primary care with a diagnosis of pneumothorax in each year from 1991 to 1995 inclusive were identified from the General Practice Research Database (GPRD). Emergency hospital admissions for pneumothorax were identified for the years 1991-4 from the Hospital Episode Statistics (HES) data. Mortality data for England \& Wales were obtained for 1950-97. Analyses of pneumothorax rates by age and sex were performed for all data sources. Seasonal and geographical analyses were carried out for the HES data.

Results-The overall person consulting rate for pneumothorax (primary and secondary combined) in the GPRD was 24.0 / 100000 each year for men and 9.8/100 000 each year for women. Hospital admissions for pneumothorax as a primary diagnosis occurred at an overall incidence of 16.7 I 100000 per year and 5.8/100 000 per year for men and women, respectively. Mortality rates were $1.26 /$ million per year for men and $0.62 /$ million per year for women. The age distribution in both men and women showed a biphasic distribution for both GP consultations and hospital admissions. Deaths showed a single peak with highest rates in the elderly. There was an urban-rural trend observed for hospital admissions in the older age group (55+ years) with admission rates in the conurbations significantly higher than in the rural areas. Analysis for trends in mortality data for 1950-97 showed a striking increase in the death rate for pneumothorax in those aged 55+ years between 1960 and 1990 , with a steep decline in the 1990s. Mortality in the younger age group (15-34 years) remained low and constant.

Conclusion-There is evidence of two epidemiologically distinct forms of spontaneous pneumothorax in England. The explanation for the rise and fall in mortality for secondary pneumothorax is obscure.

(Thorax 2000;55:666-671)
\end{abstract}

Keywords: pneumothorax; epidemiology; mortality trends

The term pneumothorax was first coined in 1803 by Itard and its clinical features were described by Laennec in 1819. ${ }^{1}$ Pneumothorax is defined as the entry of air into the pleural space. $^{2}$ Over half of pneumothoraces are traumatic (accidental or iatrogenic); the remaining occur without any preceding trauma and are labelled spontaneous. ${ }^{23}$ Spontaneous pneumothoraces can be divided into two types - primary and secondary. Primary spontaneous pneumothorax is the idiopathic variety which occurs in otherwise healthy persons. In secondary spontaneous pneumothorax an underlying disease state responsible for the pneumothorax can be identified. Although several subtypes of pneumothorax have been described, pneumothorax occurs as a single code in the International Classification of Diseases (ICD9 512).

Much has been written about the classification, aetiology, pathogenesis, clinical features, and therapeutic aspects of pneumothorax ${ }^{3}$ but there are limited quantitative data. Most of the published literature relates to analysis of specific aspects of the disease in case series of varying sizes, predominantly confined to spontaneous pneumothorax, either primary or secondary. This paper describes for the first time the epidemiology of pneumothorax in England in recent years, using three large national databases and giving information on primary care, hospital admissions, and deaths.

\section{Methods}

DATA SOURCES

Patients consulting in primary care with a diagnosis of pneumothorax in each year from 1991 to 1995 inclusive by age and sex were identified from the General Practice Research Database (GPRD). This is the largest computerised source of routine information on general practice morbidity and prescribing in England and in 1994 covered $5.6 \%$ of the population of England and Wales. ${ }^{56}$

Hospital Episode Statistics (HES) data were obtained from the Office for National Statistics (ONS) for the financial years 1990-1 to 1993-4 and from Data Sciences UK for the year 1994-5. Emergency hospital admissions for pneumothorax by age and sex were identified for the years 1991-4. These were defined as finished consultant episodes where the episode number was equal to one and where the primary reason for the emergency admission was coded as pneumothorax (ICD9 512). HES data are collected by financial year (April to March), but analysis was performed in calendar years to allow comparability with other data sources. Subsequent years were not included in the analysis because of the change from ICD9 coding to ICD10 in April 1995 (ICD code changes have been recognised to lead to artefactual changes in rates of diseases $^{7}$ ). It was not possible to identify and 
Table 1 Number of events and rates ( ${ }^{\star}$ per million person years at risk) for pneumothorax in England: patients diagnosed in the GPRD (1991-5), emergency hospital admissions (1991-4) and deaths (1991-5)

\begin{tabular}{|c|c|c|c|c|c|c|}
\hline \multirow[b]{2}{*}{ Age group } & \multicolumn{2}{|c|}{$\begin{array}{l}\text { Patient GP } \\
\text { consultations }\end{array}$} & \multicolumn{2}{|c|}{$\begin{array}{l}\text { Emergency hospital } \\
\text { admissions }\end{array}$} & \multicolumn{2}{|c|}{ Deaths } \\
\hline & Men & Women & Men & Women & Men & Women \\
\hline No. of events (all ages) & 806 & 343 & 15834 & 5766 & 150 & 77 \\
\hline Rate $^{\star}$ (all ages) & 240.1 & 98.4 & 166.7 & 58.3 & 1.26 & 0.62 \\
\hline Rate $^{\star}$ (ages 15-34) & 369.8 & 153.7 & 256.0 & 93.6 & 0.24 & 0.06 \\
\hline Rate $^{\star}$ (age $55+$ ) & 325.5 & 109.1 & 253.1 & 57.6 & 4.60 & 1.96 \\
\hline
\end{tabular}

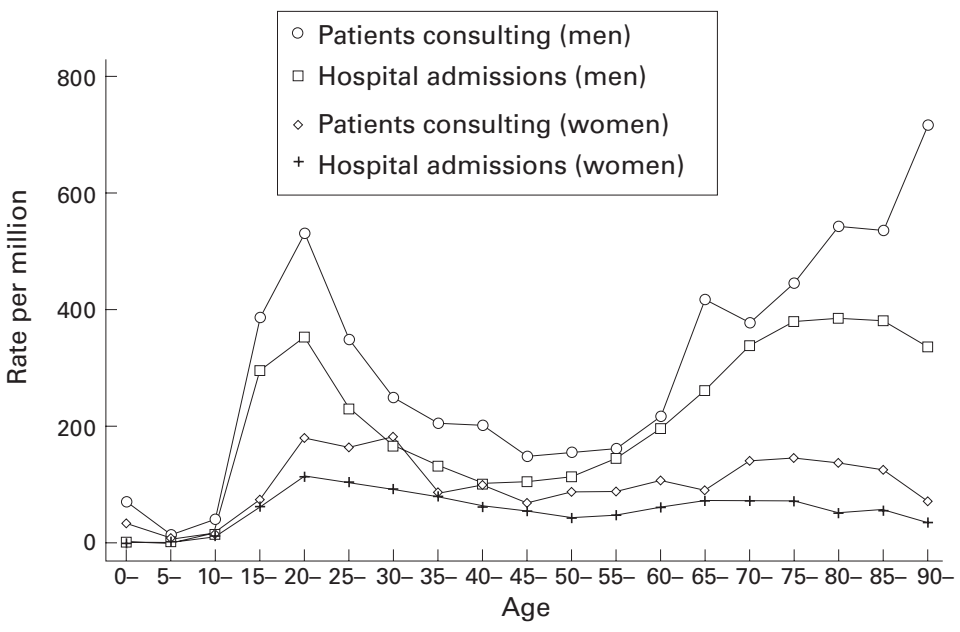

Figure 1 Rates of emergency hospital admission in 1991-4 and patients consulting a general practitioner for pneumothorax in 1991-5 in England.

exclude patients readmitted for the same condition in that year. ${ }^{8}$

Mortality data for England \& Wales by age and sex were obtained from $\mathrm{ONS}^{9}$ for the years 1950-97 for all deaths from pneumothorax. Coding for pneumothorax was not available until the 6th ICD revision introduced in 1950. Subsequent ICD revisions occurred in 1957, 1967, and 1978. Figures were collected by year in which death was registered until 1992 and by year of death from 1993.

STATISTICAL ANALYSIS

Analyses of pneumothorax rates by age and sex were performed for all data sources, but seasonal (week of year) and geographical analyses were restricted to HES because of small numbers of events in the other two data
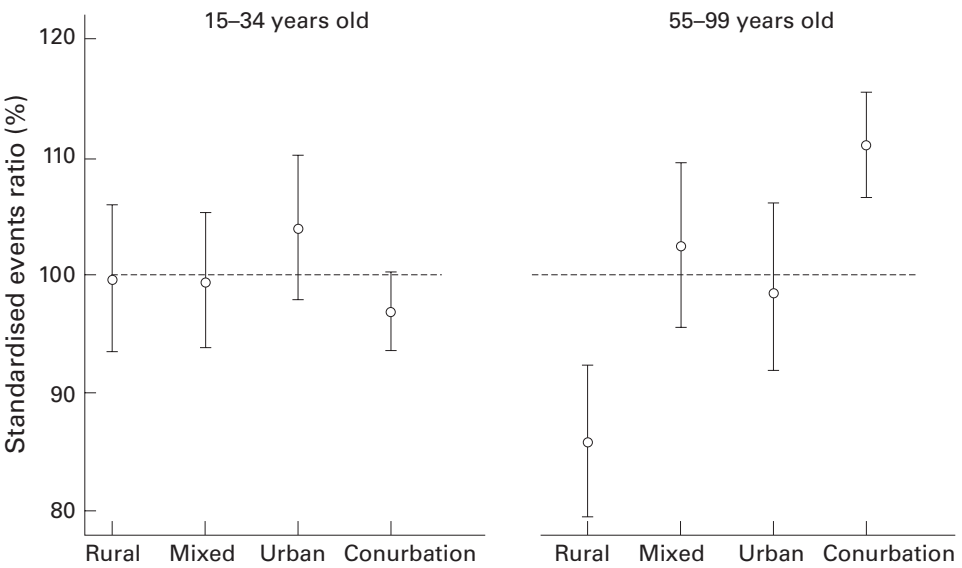

Figure 2 Age, sex, region, and year standardised emergency hospital admission ratios in England in 1991-4 by rural-urban classification. Bars represent 95\% confidence intervals. sources. All analyses were carried out using STATA version 5.0 for Windows. ${ }^{10}$

Rates for age and sex analyses for the GPRD were calculated by dividing the number of patients by age and sex with a diagnosis of pneumothorax by the person years at risk for each year to give a measure of yearly incidence of patients with pneumothorax in primary care. Mid year population estimates were obtained from the ONS. These were used to calculate incidence rates for hospital admissions for pneumothorax and mortality rates using events as the numerator and the population as denominator for mortality and HES data.

Since the age distribution for pneumothorax showed two peaks falling in ages 15-34 years and $55+$ years corresponding to primary and secondary pneumothorax, ${ }^{11}$ subsequent analyses were conducted for all ages and for these two age groups.

For seasonal (week of year) analyses, rates were calculated by dividing the number of emergency hospital admissions for each week of the year by the population years at risk derived from mid year population estimates.

In HES, geographical data on regional and district health authority (DHA) of residence were obtained. DHA of residence was used to assign an urban-rural code with four ordered categories (conurbation, urban, mixed and rural)..$^{12}$ Persons usually resident outside England were excluded. Rates were calculated by dividing numbers of events by ONS mid year population estimates which were available in five year age bands by sex for DHAs. Geographical variations by regional health authority and degree of urbanisation were compared using age and sex standardised event ratios (number of observed events divided by number of expected events $\times 100$ where the expected number of events was derived from the age and sex specific rates of pneumothorax in all regions and the particular age and sex constitution of the region concerned).

\section{Results}

The overall rate of persons consulting with pneumothorax (both primary and secondary combined) in the GPRD was 24.0 per 100000 each year for men and 9.8 per 100000 each year for women (table 1). The overall annual incidence of emergency hospital admissions for pneumothorax was 16.7 per 100000 each year and 5.8 per 100000 each year for men and women, respectively. Mortality was two orders of magnitude lower with rates of 1.26 per million per year for men and 0.62 per million per year for women.

AGE AND SEX DISTRIBUTION

The age distribution in men and women showed a biphasic distribution for both GP consultations and emergency admissions (fig 1). The highest rates for men for emergency hospital admissions and GP consultations were in the 20-24 and 80-84 year age groups. The first peak for women was at a later age than men for GP consultations (30-34 years) but was similar for hospital admissions. The 


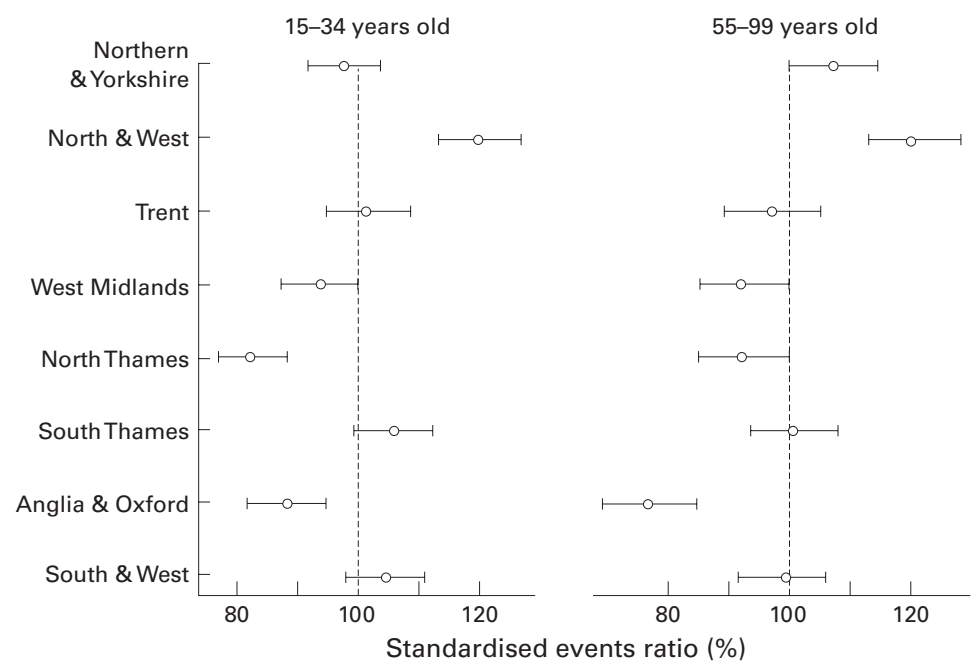

Figure 3 Age, sex, rural-urban classification, and year standardised emergency hospital admission ratios in England in 1991-4 by region (North \& West $=$ Mersey and North Western regions; South $\mathcal{E}$ West $=$ Wessex and South Western regions). Bars represent 95\% confidence intervals.

second peak for women in both data sets was at ages $70-74$ years. Deaths showed a single peak with highest rates in the elderly (85+ years).

The incidences of pneumothorax for age groups 15-34 years and 55+ are shown in table 1. Rates of patient GP consultations were slightly higher than emergency hospital admissions in both age groups. Deaths were three orders of magnitude less common than patient consultations or emergency hospital admissions in the younger age group and two orders of magnitude less common in the older age groups. The ratio of the mortality rate to emergency hospital admission rate, an approximation to case fatality, was $0.09 \%$ and $1.8 \%$ in men and $0.06 \%$ and $3.3 \%$ in women for ages 15-34 and 55+, respectively.

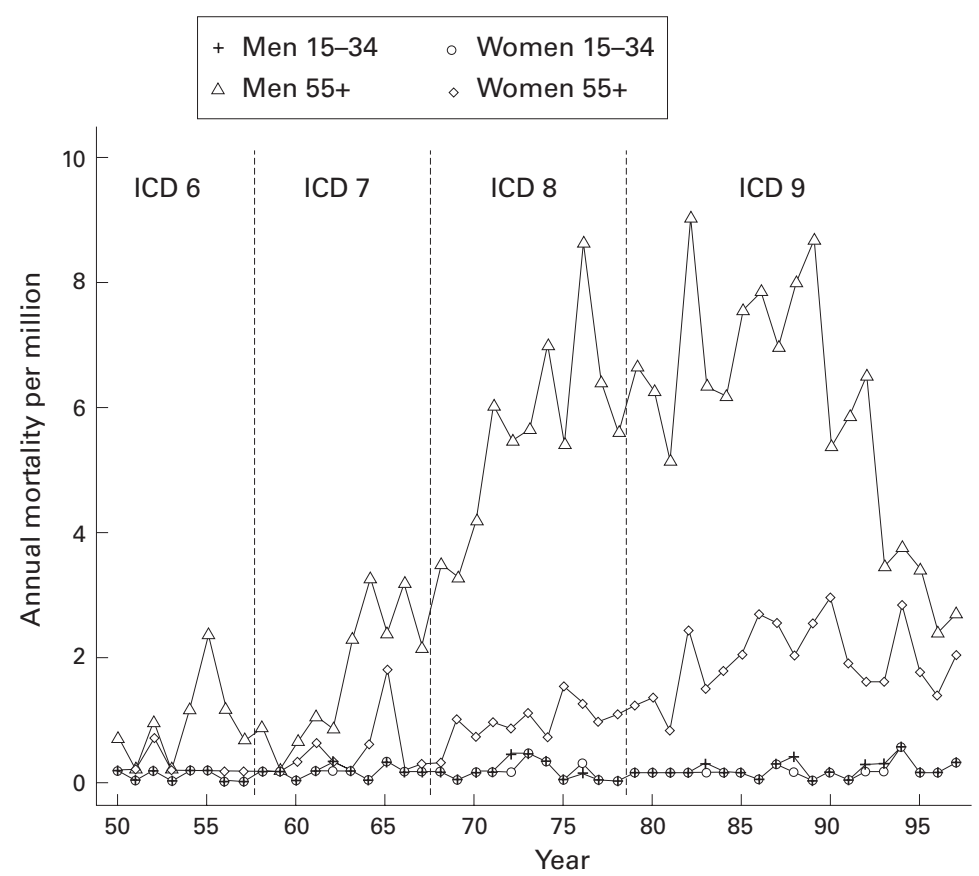

Figure 4 Mortality rates for pneumothorax in England \& Wales in 1950-97 for those aged 15-34 and 55 or over.
GEOGRAPHICAL DISTRIBUTION

The geographical distribution of emergency hospital admissions is shown in fig 2. The standardised event ratios (SERs) were similar for the conurbation, rural, urban, and mixed areas for the patients in the younger age group (15-34 years), but for those over 55 years of age there was an urban-rural trend with increasing SER from rural to urban to conurbation. The admission rates in the conurbations were significantly higher than in the rural areas.

\section{REGIONAL DISTRIBUTION}

Figure 3 shows the regional distribution of hospital admissions for pneumothorax. The highest prevalence for both younger and older age groups was in the North \& West region (Mersey and North Western). Other regions with SERs significantly higher than average were South Thames for ages 15-34 and Northern \& Yorkshire for ages 55+. Anglia \& Oxford, North Thames, and West Midlands had a significantly lower prevalence of pneumothorax in both younger and older age groups.

SEASONAL VARIATION

The weekly incidence of emergency admissions for pneumothorax showed no seasonal pattern (data not shown).

TIME TRENDS

Analysis for trends in emergency admissions (1991-4) and GP consultations (1991-5) did not reveal any significant differences over the short time period studied (not shown). The rates for pneumothorax in men over 55 years of age in 1991 and 1994 were 31.1 and 33.8 per 100000 for GP consultations and 24.0 and 23.7 per 100000 for emergency hospital admissions, respectively. However, mortality data for 1950-1997 (fig 4) showed a striking increase in the death rate for pneumothorax in subjects aged 55+ years between 1960 and 1990, with a steep decline in the 1990s. This pattern was more marked in men (more than a halving of mortality rates through the 1990s) than in women. Mortality in the younger age group (15-34 years) remained low and constant.

\section{Discussion}

This study found overall incidence rates for pneumothorax of 16.8 per 100000 per year for persons consulting their GP and 11.1 per 100000 per year for emergency hospital admissions. These rates are slightly higher than rates quoted in two previous studies, but similar to those found in another two studies, one in Sweden and one in Scotland (table 2).

PROBLEMS WITH COMPARING STUDY RATES WITH RATES DERIVED FROM ROUTINE DATA

It may be difficult to compare directly the rates we derived from the routine data with those from specific studies of spontaneous pneumothorax as the types of measures obtained differ. Death rates derived from mortality data represent person incidence rates. The rates derived from HES represent episode incidence rates 
Table 2 Incidence rates of pneumothorax in different populations (all rates expressed per 100000 per year)

\begin{tabular}{|c|c|c|c|c|c|}
\hline Study location & $\begin{array}{l}\text { Period of } \\
\text { study }\end{array}$ & $\begin{array}{l}\text { Pneumothorax } \\
\text { (all types) }\end{array}$ & $P S P$ & $S S P$ & Comments \\
\hline \multicolumn{6}{|l|}{ UK } \\
\hline Glasgow $^{11}$ & $1970 \mathrm{~s}$ & 7.8 & & & $\begin{array}{l}\text { Hospital admissions } \\
\text { to one centre }\end{array}$ \\
\hline Dundee $^{13}$ & $1976-81$ & 11.7 & & & $\begin{array}{l}\text { Hospital admissions } \\
\text { to one centre }\end{array}$ \\
\hline \multicolumn{6}{|l|}{ Outside UK } \\
\hline $\begin{array}{l}\text { Stockholm, } \\
\text { Sweden }^{14}\end{array}$ & 1980 & $\begin{array}{l}28.0 \text { (men) } \\
10.0 \text { (women) }\end{array}$ & & & $\begin{array}{l}\text { Hospital contacts } \\
\text { within a county }\end{array}$ \\
\hline $\begin{array}{l}\text { Minnesota, } \\
\text { USA }^{15}\end{array}$ & $1950-74$ & 7.9 & $\begin{array}{l}7.7 \text { (men) } \\
1.3 \text { (women) }\end{array}$ & $\begin{array}{l}5.4 \text { (men) } \\
1.9 \text { (women) }\end{array}$ & $\begin{array}{l}\text { Based on } 141 \text { cases } \\
\text { identified from } \\
\text { community health } \\
\text { records }\end{array}$ \\
\hline
\end{tabular}

PSP = primary spontaneous pneumothorax; SSP = secondary spontaneous pneumothorax.

relating to emergency hospital admission-a person may be counted more than once within a given year. Reported recurrence rates vary from $20 \%$ to $60 \%$ for the first occurrence and the risk increases with each subsequent episode. ${ }^{16}{ }^{17}$ The rates derived from the GPRD for a single year were annual period prevalence rates since multiple consultations for pneumothorax by a single person were counted only once within each year. We did not link GPRD data between years as persons with recurrent pneumothoraces in subsequent years (but not in the same year) would have been counted twice, so that GPRD rates for 1991-5 may slightly overestimate the five year period prevalence rate.

Additional problems in comparing data from different sources relate to the way in which the data were collected. The GPRD was designed to record all "significant" events such as consultations resulting in a referral and "events which the partner will require to be reminded of at a later date", which may include information from hospital letters including traumatic and iatrogenic pneumothoraces and coroners' reports, in addition to patient consultations. ${ }^{6}$ However, a previous comparison of the GPRD with the Fourth Morbidity Survey in General Practice in 1991-2, which specifically recorded patient consultations, suggested that rates were similar in both data sources. $^{18}$

Patients who were managed solely in accident and emergency departments are not easily identified from routine data and are not included in HES. The British Thoracic Society guidelines on the management of pneumothorax recommends admission only for patients with primary spontaneous pneumothorax who require intercostal chest tube drainage after having failed simple needle aspiration or for those with underlying diseased lung. ${ }^{19}$ In the Scottish study it was shown that $32 \%$ of all episodes of pneumothorax did not require intercostal chest tube drainage ${ }^{13}$ so as many as one third of patients with primary spontaneous pneumothorax may be managed solely in accident and emergency departments. It is possible that some of these persons may have been ascertained in the GPRD by information from letters to the GP.

For hospital admissions we attempted to exclude all pneumothoraces developing after admission (iatrogenic and barotrauma due to positive pressure ventilation) by selecting from HES only emergency admissions with a primary diagnosis of pneumothorax. It is likely that this also excluded most admissions for traumatic pneumothorax as the primary reasons for admission for most of these patients will be multiple injuries.

It is likely that mortality in pneumothorax, which is greater in the older subjects, can be attributed to the associated co-morbidity rather than to pneumothorax itself. Most of the earlier studies on the management of pneumothorax have recorded very occasional deaths with primary spontaneous pneumothorax and low mortality rates for secondary spontaneous pneumothorax. ${ }^{13}$ In a study from the USA ${ }^{20} 12$ out of 35 patients with pneumothorax and AIDS had died whereas only three out 90 other patients with spontaneous pneumothorax died, signifying that mortality in pneumothorax is due to host factors rather than deficient treatment.

RISK FACTORS FOR SPONTANEOUS

PNEUMOTHORAX

Smoking is suggested as a risk factor for primary spontaneous pneumothorax ${ }^{21} 22$ and a study from Sweden showed its incidence was affected by changes in the sale of cigarettes. ${ }^{23}$ There are several recognised causes of secondary spontaneous pneumothorax including pulmonary emphysema, pneumonia, primary and secondary malignancy, bronchial asthma, pulmonary fibrosis, and cystic fibrosis. The aetiology of secondary spontaneous pneumothorax will depend on the prevalence of these diseases in the population under study. In a large Japanese study of spontaneous pneumothorax in women ${ }^{24}$ tuberculosis was the commonest cause of secondary spontaneous pneumothorax while US data have shown a changing clinical spectrum over time of spontaneous pneumothorax with an increasing number of cases being secondary to the pulmonary complications of AIDS. ${ }^{20}$ Information on co-morbidity was not available in the present study. The most common cause of secondary spontaneous pneumothorax in the UK in previous studies was chronic obstructive pulmonary disease (COPD) which accounted for $70-80 \%$ of all patients with the condition. ${ }^{13}{ }^{17}$ This is also strongly related to cigarette smoking.

\section{AGE DISTRIBUTION}

The bimodal age distribution in our data was similar to that previously reported. ${ }^{11}{ }^{1325}$ The peak in the younger age group (15-34 years) and older age groups (55+) can be mainly attributed to primary and secondary spontaneous pneumothorax, respectively. In the study from Scotland ${ }^{13}$ (table 2) $90 \%$ of patients with pneumothorax under the age of 35 had no previous history of lung disease while $80 \%$ of patients over the age of 50 years had preexisting lung disease. Studies that have focused strictly on primary spontaneous pneumothorax, excluding all other forms of pneumothoraces, have shown a monophasic age distribution with the peak falling in the 15-35 year age 
group, ${ }^{172426}$ which is comparable to our findings.

Pneumothorax is distinctly rare among children and we confirmed a very low prevalence in age groups less than 15 years (fig 1 ). In a study from the $\mathrm{USA}^{27}$ only one child and 3.4 infants per 10000 admissions in that age group had had a pneumothorax. Another study from the USA recorded only 17 patients with spontaneous pneumothorax under the age of 16 years over a 12 year period. ${ }^{28}$ Both these studies showed that spontaneous pneumothorax in children and infants is almost always secondary to some underlying disease.

SEX DIFFERENCES

Men are more prone to sustain a pneumothorax than women. The M:F ratio in this study $(2.7: 1)$ is similar to that reported earlier in the UK ( $3: 1^{11}$ and $\left.2: 1^{13}{ }^{17}\right)$, but lower than US data which showed $M: F$ ratios of $6.2: 1$ for primary spontaneous pneumothorax and 3.2:1 for secondary spontaneous pneumothorax. ${ }^{15}$ The higher incidence of spontaneous pneumothorax in men has been attributed to several factors such as higher rates of smoking, ${ }^{21} 22$ taller body habitus, ${ }^{24}$ and differences in mechanical properties of the lung. ${ }^{29}$

Certain rare causes of pneumothorax are specific to women - for example, catamenial pneumothorax and lymphangioleiomyomatosis ${ }^{2}$ and women are also more prone to recurrence of pneumothorax than men. ${ }^{17}$ Women in England seem to have a higher incidence of pneumothorax than in other countries (table 2), but we were unable to discern whether this finding is because of the way the data are collected or as a result of aetiological factors.

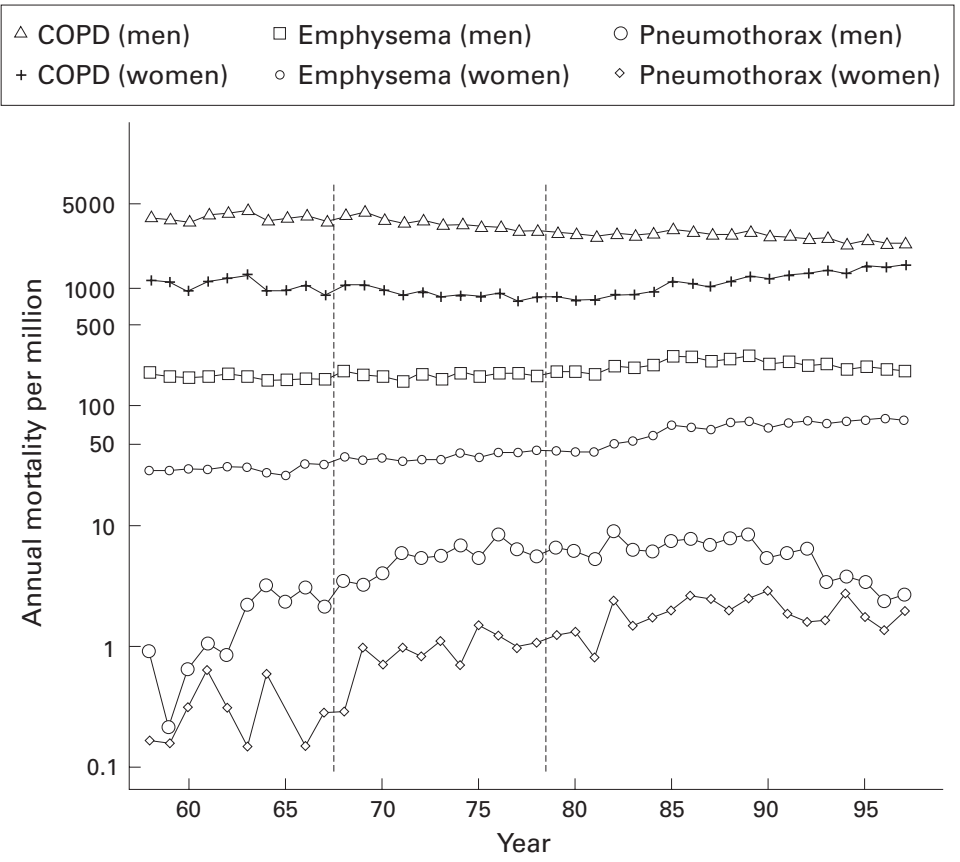

Figure 5 Mortality rates for chronic obstructive pulmonary disease (COPD), emphysema, and pneumothorax in England \& Wales in 1958-97 for those aged 55 and over. Vertical scale is logarithmic.
GEOGRAPHICAL DIFFERENCES

The significantly higher admission rate for pneumothorax in conurbations than in rural areas in subjects aged over 55 years probably reflects the higher prevalence of COPD in conurbations; similar analyses of hospital admissions and GP consultations for COPD also showed a rural-urban gradient in this age group (not shown). The regional distribution of pneumothorax follows a similar trend with more cases being reported from the areas with a known higher prevalence of both smoking and COPD. These geographical differences were not seen in younger patients (15-34 years) with pneumothorax (who largely represent cases of primary spontaneous pneumothorax).

\section{SEASONALITY}

Previous reports have suggested a seasonal variation in the incidence of pneumothorax, increased incidence of spontaneous pneumothorax having been linked to falling humidity, ${ }^{30}$ a fall in ambient air pressure, ${ }^{31}$ and phases of the moon. ${ }^{32}$ Although a Scottish study showed decreased admissions during the summer months, ${ }^{13}$ we did not find a seasonal pattern in the weekly admission records for any age group. This is perhaps surprising as it might be supposed that a winter excess of secondary spontaneous pneumothorax would be found associated with increased respiratory infections leading to coughing and increased hyperinflation in patients with chronic bronchitis or emphysema, respectively.

\section{TIME TRENDS}

We did not show any significant changes in incidence as represented by hospital admissions or persons consulting in general practice during the early 1990 s, but mortality from pneumothorax in older men declined dramatically over this period, having increased markedly between 1960 and 1990. Mortality rates also fell in older women, although to a lesser degree. These changes suggest a recent change in the natural history of secondary spontaneous pneumothorax. A comparison of trends in COPD, emphysema, and pneumothorax mortality between 1958 and 1997 (fig 5, emphysema was not separately tabulated in 1950-7) suggested that the falling mortality from 1990 onwards appears too abruptly to represent solely changes in cohort smoking patterns. The rate of decline in deaths from pneumothorax in men was faster than the decline in deaths from COPD or emphysema, and in women the deaths from COPD and emphysema were rising between 1985 and 1995 while those for pneumothorax declined. This can only be partly explained, if at all, by better management as a result of the publication in 1993 of the BTS guidelines on the management of pneumothorax. ${ }^{19}$ Some of the deaths may not be due to spontaneous pneumothorax-for instance, barotrauma in association with assisted mechanical ventilation may be recorded as the immediate cause of death. Further investigation using multiple cause coding or clinical record enquiry will be required to explain this phenomenon. 
CONCLUSIONS

There is evidence of two epidemiologically distinct forms of spontaneous pneumothorax in England. At younger ages it does not have a defined urban-rural or regional pattern and the rates have not changed in recent years. In older age groups geographical variations in the incidence of spontaneous pneumothorax generally parallel the epidemiology of COPD which, in turn, is strongly influenced by patterns of smoking. However, in the early 1990s death rates from pneumothorax in the elderly showed an abrupt decline which was not parallelled by mortality from COPD and emphysema. This is unlikely to be explained by changes in smoking habits and deserves further investigation.

We thank Dr Jen Hollowell and Ms Rosie McNiece for providing the GPRD data and giving advice on its interpretation.

DG is an Associate Professor of Pulmonary Medicine at the Postgraduate Institute of Medical Education and Research, Chandigarh, India on a visiting fellowship to the UK sponsored by the Raj Nanda Pulmonary Diseases Research Trust in India, The Royal College of Physicians UK, and the British Thoracic Society. He thankfully acknowledges the support from all Society. He thankfully acknowledges the suppor

The collation and comparison of routine data sources relating
concerned to enable him to undertake this work.

to pneumothorax was part of a project funded by the to pneumothorax was part of a project funded by the
Department of Health and carried out at St George's Hospital Medical School.

1 Laennec RTH. Traite de l'auscultation mediate et des maladies des poumons et du coeur. Tome Second. Paris, 1819.

2 Light RW. Pneumothorax. In: Pleural diseases. 3rd edn. Baltimore: Williams \& Wilkins, 1995: 242-77.

3 Schramel FMNH, Postmus PE, Vanderschueren RGJRA. Current aspects of spontaneous pneumothorax. Eur Respi f 1997; 10:1372-9.

4 Bense L. Spontaneous pneumothorax. Chest 1992;101:8915 Key

Key health statistics in general practice. London: The Stationery Office, 1996

6 Hansell AL, Hollowell J, Nichols T, et al. Using the General Practice Research Database for respiratory epidemiology: a comparison with the Fourth Morbidity Survey in general practice. Thorax 1999;54:413-9.

7 Marks G, Burney PGJ, Charlton J, Murphy M, eds. Diseases of the respiratory system. In: The health of adult Britain of the respiratory system. In: The health of adult Britain

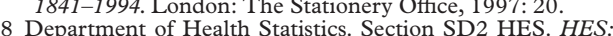
The Book. London: Department of Health, 1998.

9 Office for National Statistics. Twentieth century mortality: 95 years of mortality data in England and Wales by age, sex, year and underlying cause. CD-ROM. Office for National Statistics, 1997.
10 Intercooled Stata. 5.0 for Windows 95. USA: Stata Corporation Texas, 1997 .

11 Ferguson LJ, Imrie CW, Hutchison J. Excision of bullae without pleurectomy in patients with spontaneous pneumothorax. Br F Surg 1981;68:214-6.

12 Committee on the Medical Aspects of Air Pollution. Asthma and outdoor air pollution. London: HMSO, 1995.

13 Primrose WR. Spontaneous pneumothorax: a retrospective review of aetiology, pathogenesis and management. Scott Med f 1984;29:15-20.

14 Bense L, Wiman L-G, Nilsson B. On etiology of spontaneous pneumothorax. Stresa: IV SEP Congress, 1985: A17.

15 Melton LJ III, Hepper NG, Offord KP. Incidence of spontaneous pneumothorax in Olmested County, Minnesota: 1950-1974. Am Rev Respir Dis 1979;120:1379-82.

16 Milanez JR, Vargas FS, Filomeno LT, et al. Intrapleural talc for prevention of recurrent pneumothorax. Chest 1994;106: $1162-5$.

17 Sadikot RT, Green T, Meadows K, et al. Recurrence of primary spontaneous pneumothorax. Thorax 1997;52:805-9.

18 Lee PN, Fry JS, Forey BA. Trends in lung cancer, chronic obstructive lung disease and emphysema death rates for obstructive lung disease and emphysema death rates for cigarette smoking. Thorax 1990;45:657-65.

19 Miller AC, Harvey JE, on behalf of Standards of Care Committee, British Thoracic Society. Guidelines for management of spontaneous pneumothorax. BMf 1993;307:1146.

20 Wait MA, Estrera A. Changing clinical spectrum of spontaneous pneumothorax. Am f Surg 1992;164:528-31.

21 Bense L, Eklund G, Odont D, et al. Smoking and the increased risk of contracting spontaneous pneumothorax. Chest 1987;92:1009-12.

22 Jansveld CAF, Dijkman JH. Primary spontaneous pneumothorax and smoking. BMF 1975;4: 559-60.

23 Bense L, Wiman LG. Time relation between sale of cigarettes and the incidence of spontaneous pneumothorax. Eur F Respir Dis 1987;71:362-4.

24 Nakamura H, Konishiike J, Sugamura A, et al. Epidemiology of spontaneous pneumothorax in women. Chest 1986; 89:378-82.

25 Ruckley CV, McCormack RJM. The management of spontaneous pneumothorax. Thorax 1966;21:139-44.

26 Nakamura H, Izuchi R, Hagiwara T, et al. Physical constitution and smoking habits of patients with idiopathic spontaneous pneumothorax. Fapanese f Med 1983;22:2-8.

27 Alter SJ. Spontaneous pneumothorax in infants: a 10-year review. Pediatr Emerg Care 1997;13:401-3.

28 Wilcox DT, Glick PL, Kramanoukian HL, et al. Spontaneous pneumothorax: a single institution 12-year experience in patients under 16 years of age. $\mathcal{F}$ Pediatr Surg 1995;30:1452-4.

29 Taussig LM, Cota K, Keltenborn W. Different mechanical properties of lung in boys and girls. Am Rev Respir Dis 1981;123:640-3.

30 Ozenne G, Poignie P, Lemercier JP, et al. Meteorological conditions and spontaneous pneumothorax. Retrospective study of 165 cases in Rouen area. Rev Pneumol Clin 1984; 40:27-33.

31 Bense L. spontaneous pneumothorax related to falls in atmospheric pressure. Eur 7 Respir Dis 1984;65:544-6.

32 Sok M, Erzen J. The role of phases of the moon in development of spontaneous pneumothorax. Radiol Oncol 1996;30: $55-7$. 